\title{
On the concept of pedodiversity and its measurement. A reply
}

\author{
J.J. Ibáñez ，S. de Alba
}

\section{Introduction}

In the preceding Letter, Camargo (1999) polemicised about the use of mathematical tools for studying ecological diversity in soil taxonomy as described in our previous Discussion Paper (Ibáñez et al., 1998a,b). Any pedologist who peruses the letter would realise that, behind the criticism and opinions, there lies a certain discrepancy concerning Camargo's point of view on diversity analysis. It would be trivial to override his arguments if the Geoderma readership were generally aware of certain debates in ecology, biotaxonomy and biosystematics. After reading the documents referenced in this Reply, any reader interested in the topic would probably agree that Dr. Camargo's opinions, which at first sight are reasonable, are also partial and out of context.

\section{On the concept of biodiversity}

Huston discusses the meaning of diversity in his popular monograph "Biological Diversity"' (1994, p. 65):

The concept of diversity has two primary components, and two unavoidable value judgments. The primary components are statistical properties that are common to any mixture of different objects, whether the objects are balls of 
different colours, segments of DNA that code for different proteins, species or higher taxonomic levels, or soil types or habitat patches on a landscape. Each of these groups of items has two fundamental properties: (1) the number of different types of objects (e.g., species, soil types) in the mixture or sample; and (2) the relative number or amount of each different type of object. The value judgements are (1) whether the selected classes are different enough to be considered separate types of objects; and (2) whether the objects in a particular class are similar enough to be considered the same type. On these distinctions hangs the quantification of biological diversity.

\section{On the algorithms and distribution models to assess pedodiversity}

In our Discussion Paper (1998a), we applied the mathematical tools most used by ecologists, as evidenced by Magurran (1988). From Magurran (1988), whilst some ecologists prefer other indices, it should be considered that: (i) Shannon's index is the most used; (ii) in order to allow comparison of results, employing the most used tools is recommendable; (iii) all indices give correlated values, and (iv) the use of some or others is more a matter of vogue or taste than scientific criteria. In the current state of the art of enviromnental diversities indices, any postulation about the superiority of a particular index is totally groundless.

\section{On the validity of diversity analysis to any scientific discipline}

The conceptual and methodological contribution of the concept and measurements of biological diversity (some of which originated in the information theory) in theoretical ecology is unquestionable. However, ecology is nothing more than one of several disciplines which make use of the concept of diversity. In particular, biotaxonomists have often reproached ecologists for the exclusive appropriation of this topic (e.g., Eldredge, 1992; Minelli, 1993; Mayr, 1995). For Simpson (1961, p. 7): "systematics is the scientific study of the kinds and diversity of organisms and of any and all relationships among them", so that taxonomy is largely seen as the practical branch of systematics (Minelli, 1993).

The first predictive estimate of the number of existing species of plants and animals at world level was proposed as far back as 1778 by Zimmerman (in Minelli, 1993, p. 126), almost a century before publication of Darwin's theory and the former definition of ecology, as proposed by Haeckel in 1866 (e.g., McIntosh, 1985; Mayr, 1995). On the other hand, the first appraisal of the diversity-area relationships is due to $G$. White, an 18 th century naturalist (Worster, 1977 in McIntosh, 1985). The ecologist, Williamson (1981), also 
addressed the interest of studying the diversity of soil and geological types, while other authors confirm how enviromnental heterogeneity, including soil types, is strongly and positively correlated with species diversity (e.g., Harner and Harper, 1976; Anderson, 1978).

\section{On the ecological implications of biological diversity}

With regard to this topic, it suffices to say that the possible role postulated for diversity in the structure and stability of ecosystems has not yet been demonstrated (there are hypotheses but not validated theories). This topic is still a controversial subject (e.g., Peters, 1991; Mayr, 1995; Rosenweig, 1995).

\section{On taxonomic pedodiversity "vs." spatial variability of soil properties}

Soil taxa and soil properties are independent (not synonymous) concepts and it is not pertinent to compare them. Therefore, calculating their respective spatial significance by means of geostatistical tools in the case of spatial variability of soil properties, or by means of diversity indices and distribution models for soil taxa, should be considered complementary instead of equivalent, reiterative or implicit. For example, in our Reply (Ibáñez et al., 1998b), we stated, at least for a specific area in Central Spain, the "taxonomic pedodiversity" and "spatial variability of some soil properties" were inversely correlated (Saldaña and Ibáñez, 1998) (awaiting publication). If Dr. Camargo considered carefully the Reply of Odeh (1998), he might agree on what Odeh states properly, that using geostatistical tools "taxonomic pedodiversity" may be quantified too, as well as the fact that the concept of pedodiversity could be applied to other levels of the hierarchy of pedological entities. We also affirmed this (Ibáñez et al. 1998a,b).

\section{On taxa diversity and the continuum dilemma}

The next definition is a transcription of Article 2 of the "Convention on Biological Diversity" of the United Nations Conference on the Enviromnent and Development (UNEP, 1992):

Biological diversity means the variability among living organisms from all sources including, inter alia, terrestrial, marine and other aquatic systems and the ecological complexes of which they are part; this includes diversity within species, between species and of ecosystems.

Therefore, the study of ecological diversity is not restricted to that of species diversity so neither is it pertinent to limit oneself to the comparison between the 
attributes of pedotaxa and biotaxa. As almost all plant ecologists recognise, changes between types of vegetation occur in a gradual, fuzzy fashion (e.g., Whittaker, 1978; Peters, 1991). Thus, the delimitation of vegetation in types is arbitrary (Sattler, 1986) and, for many biologists, it is often more appropriate to look for order that is not expressed by systems of discrete classes but rather by fuzzy sets (e.g., Sattler, 1986). Therefore, it will have to be admitted that, at least, there are not more conceptual problems for quantifying diversity of soil entities than ecosystem or plant community diversities.

\section{On the continuum dilenmma in pedology, ecology and biotaxonomy}

Ibáñez et al. (1998b) gave their opinion on the soil continuum dilemma. We doubt whether many pedologists disagree as regards the nature of the soil continuum. What Camargo (1999) would seem to suggest is that the nature of the soil continuum invalidates drawing up "natural" soil classifications and, as a corollary, the estimation of pedodiversity. Nevertheless, the first target of any scientific discipline is to place the objects and processes of interest in order and classify them. There is no epistemological argument for a continuum entity not to be separated into discrete units, if carried out reasonably. Is this not the same case as that of the classifications of plant communities and ecosystems?

\section{On fuzzy logic, soil continuum and soil classification}

Ibáñez et al. (1998b) suggest that statistical approaches based on fuzzy sets are a powerful tool for tackling many quantitative aspects of the soil system (including its classification). Fuzzy sets are also useful for analysing and classifying vegetation (e.g., Andreucci et al. 1999) and biotaxonomy, despite having been so very little used so far in biology (Sattler, 1986). Contrary to what possibly is meant by Camargo, McBratney and De Gruijter (1992) would not seem to wish to invalidate traditional soil classifications but improve them or provide supplementary alternatives. As Webster (1994) states, “ “.. Geostatistics does not negate the earlier model of classification in its entirety; rather, it is complementary, and the two can be combined...".

\section{On the principle of complementarity}

As regards the nature of the soil continuum dilemma, Camargo criticizes our appeal to Bohr's Principle of Complementarity (the same as on our perception of the continuum). Niels Bohr applied it to ethical and philosophical situations, as well as to quantum mechanics (Bohr, 1958, 1963; Dyson, 1995, Chapter 16). 
The Principle of Complementarity states that nature is too complex for it to be described from any singular point of view. In order to obtain a suitable description, things must be looked at from various perspectives, even though they may seem simultaneously inapplicable. Here, there is no logical contradiction at all (e.g., Heisenberg 1958; Dyson, 1995).

\section{Post scriptum: naturalia/artificialia and the continuum dilemma in biology}

For many biological taxonomists and systematics, species are not "natural" entities (see Sattler, 1986; Minelli, 1993), neither can it be claimed that there is a single concept of species able to account for the huge diversity of biological organisms (Van Valen, 1976; Sattler, 1986; Minelli, 1993; Mayr, 1995; O'Donnell et al., 1995). In fact, ontologically, if biological species and other biotaxa are "natural" or not is not a scientific problem but metaphysical one (Sattler, 1986).

From the above considerations, it should be realized that even the taxonomy of different biological entities (e.g., species, ecosystems, etc.) is closely involved with the continuum dilemma. Nevertheless, current ecology and related disciplines do not reject the conceptual and methodological potential provided by the studies on biodiversity. At this point, in spite of the limitations of current soil classification systems, it is clear that, for the progress of pedology, the conceptual frame and the statistical procedures arisen from the diversity analysis are of great interest. The important fact is that the diversity analysis represents a powerful method to analyze the spatial heterogeneity of soil landscapes as well as their relationships with other biotic and abiotic landscape factors.

\section{Acknowledgements}

We are indebted to several colleagues whose constructive comments have helped to improve the presentation, including Dr. G. Almedros, R. Espejo, A. López-Lafuente and Vincenzo Zucarrello.

\section{References}

Anderson. J.M., 1978. Inter- and in ra-habitat relationships between woodland Cryptostigmata species diversity and diversity of soil and litter microhabitats. Oecologia 32, 341-348.

Andreucci, F., Biondi, E., Feoli, E., Zucarello, V., 1999. Modelling environmental responses of plant associations by fuzzy set theory: an example from halophilous vegetation of the Northern Adriatic Coast (Italy). Coenoses, (In press). 
Bohr, N., 1958. Natural philosophy and human cultures. In: Essays 1932-1957 on Atomic Physics and Human Knowledge. The Philosophical Writings of Niels Bhor II Wiley, New York, pp. 23-31.

Bohr, N., 1963. Quantum physics and philosophy: causality and complementarity. In: Essays 1958-1962 on Atomic Physics and Human Knowledge. The Philosophical Writings of Niels Bhor III Wiley, New York, pp. 1-7.

Camargo, J.A., 1999. On the concept of pedodiversity and its measurement. Letter Geodernna.

Dyson. F.J., 1995. From Eros to Gaia. Penguin. USA, 384 pp.

Eldredge, N., 1992. Introduction: systematics, ecology and the biodiversity crisis. In: Eldredge, N. (Ed.), Systematics, Ecology and the Biodiversity Crisis. Columbia Univ. Press, New York, pp. vii-ix.

Hamer, R.F., Harper, K.T., 1976. The role of area, heterogeneity, and favorability in plant species diversity of pinyon-juniper ecosystems. Ecology 57, 1254-1263.

Heisenberg, W., 1958. The Physicist's Conception of Nature. Translated by In: Pomerans, A.J. (Ed.), Harcourt, Brace, New York.

Huston. M.A., 1994. Biological Diversity. Cambridge Univ. Press, Cambridge, 681 pp.

Ibáñez, J.J., De-Alba, S., Lobo, A., Zucarello, V., 1998a. Pedodiversity and global soil patterns at coarser scales. Geodenna 83, 199-201, (with discussion).

Ibáñez, J.J., Saldaña, A., De-Alba, S., 1998b. Pedodiversity and global soil patterns at coarser scales. In: Ibáñez, J.J., De-Alba, S., Lobo, A., Zucarrello, A.V. (Eds.), Geoderma 83, 206-214.

Magurran, A.E., 1988. Ecological Diversity and Its Measurement. Croom Helm, London. 179 pp.

Mayr, E., 1995. This is Biology. Translated into Spanish by Editorial Debate from English., Madrid, 326 pp.

McBramey, A.B., De Grujjter, J.J., 1992. A continuum approach to soil classification by modified fuzzy $k$-means with extragrade. Geodernna $54,39-64$.

McIntosh, R.P., 1985. The Background of Ecology. Concept and Theory. Cambridge Univ. Press, Cambridge, 383 pp.

Minelli, A., 1993. Biological Systematics. The State of the Art. Chapman \& Hall, London, 387 pp.

Odeh, I.O.A., 1998. Pedodiversity and global soil patterns at coarser scales. In: Ibáñez, J.J., De-Alba, S., Lobo, A., Zucarrello, V. (Eds.), Geoderna 83, 203-205.

O'Donnell, A.G., Goodfellow, M., Hawksworth, D.L., 1995. In: Hawksworth, D.L. (Ed.), Biodiversity: Measurement and Estmation. Chapman \& Hall in association with the Royal Society, London. pp. 65-73.

Peters, R.H.A., 1991. Critique for Ecology. Cambridge Univ. Press, Cambridge, USA, 366 pp.

Rosenweig, M.L., 1995. Species diversity in space and time. Cambridge Univ. Press, Cambridge, $436 \mathrm{pp}$.

Saldaña, A., Ibáñez, J.J., 1998. Pedodiversity and soil variability, what is the relationship? To be submitted.

Sattler, R., 1986. Biophilosophy. Analy and Holis

Simpson. G.G., 1961. Principles of Animal Taxonomy. Columbia University Press, New York, $247 \mathrm{pp}$.

UNEP, 1992. Convention on biological diversity. UNEP, Nairobi, June.

Van Valen, L., 1976. Ecological species, mul ispecies, and oaks. Taxon 25, 233-239.

Webster, R., 1994. The development of pedometrics. Geoderna 62, 1-15.

Whittaker, R.H., 1978. Direct gradient analysis. In: Whittaker, R.H. (Ed.), Ordination of Plant Communities. Junk, The Hague, pp. 7-50.

Williamson, M., 1981. Island Populations. Oxford Univ. Press, 286 pp. 